\title{
Diet and the Conceiving Mother
}

\section{Jonathan Johnson, Arsalan Aslam, M.Salman Alam \& Ahmad Yaar Baig}

Agha khan University Hospital, Nursing Department

Corresponding Author: johnjonathan09@gmail.com

\section{Abstract}

There is a lack of awareness among the people of the community regarding diet during pregnancy. Diet is not only important for pregnant women but is equally important for female of pubertal age, as insufficient nutrients during this time may cause serious consequences in later life. At the community level it is important to make awareness for people about a balanced diet, it's important during reproductive age and for a pregnant woman. At the institutional level it is important to make healthcare accessible for the clients and make daily checkups possible, affordable and accessible for the pregnant women and also for the client who are in their reproductive age. In a nutshell, diet is an essential component to look after especially for women in her reproductive health and for pregnant women. Development of a proper diet plan for the mother, awareness programs on importance of diet and making healthcare accessible for the clients are some of the necessary steps needed for dealing with this problem.

Keywords

Community level, Institutional level, Awareness, Insufficient nutrients, Reproductive age

\section{Introduction}

A healthy and balanced diet is important throughout your age and it becomes more important when a woman is pregnant. As a pregnant woman is not only eating for herself but also for the growing life inside her. A healthy and balanced diet during pregnancy not only hampers the women's health but also aids the growth and development of the life inside her. According to World Hunger Education Service (2012) Malnutrition is a nutritional disorder, this is associated with unbalanced or insufficient or excessive food intake or by reduce absorption, digestion or use of foods. During my student community clinical at a local community, I was able to interact with a family of six members; it was a nuclear family (Rose, D. and Oliveira, V., 1997). Mother was expecting a child and was a house wife; father was a supervisor at a construction site. The father was a known case of diabetes and hypertension and the mother had number of health issues, she was fatigued, anemic and appeared wasted and weak. When the mother was asked, she had no awareness about what is a balanced and healthy diet. She described her diet like whatever is left after the whole family has eaten is given to her which is usually not enough for a pregnant woman.

There could be many reasons contributing to malnutrition during pubertal age and during pregnancy. Firstly, lack of awareness among the people of the community regarding diet during pregnancy and also about a balanced diet. Secondly, presence of diseases hindering absorption or digestion of food. Thirdly, the economic condition of the family, which in case of my client was the biggest reason. The family was not able to afford balance diet due to financial crises (Valenzuela, et al 2013).

Diet is not only important for pregnant women but is equally important for female of pubertal age as insufficient nutrients during this time may cause serious consequences in later life. Diet have direct effect on the ability to conceive and diet also plays an important 
role in preventing reproductive organs related diseases which includes prostate and ovarian cancer (Ohlhorst, et al., 2013). Reproduction in women requires more energy than in males, the nourishing of the offspring both during pregnancy and lactation requires energy expenditure which is the biggest change female makes during her lifetime which makes female more sensitive to disruption due to nutritional deprivation than men (Crosignani, 2006). The client with whom I interacted with, was $45 \mathrm{~kg}$ and had a $\mathrm{BMI}$ of 17.4 in relation to this a meta-analysis study found that underweight women were at a higher risk of preterm birth. Moreover, according to the same article body weight is considered to have a direct effect on health including infertility (Sharma, et al, 2013).

To overcome this rising problem interventions are needed to be taken at individual, community and institutional level. Firstly, at the individual level, it is important to develop a strict diet plan for a conceiving mother that consists of all nutrients necessary for her nourishment and growth of the offspring. The diet plan should have components of carbohydrates, proteins, certain amount of fats and probiotics. Moreover, the diet plan should be made flexible by giving alternatives that the family can easily afford and access. Secondly, at the community level it is important to aware the people about a balanced diet, it's important during reproductive age and for a pregnant woman (Vitolo, M., Campagnolo, P. and Gama, C., 2007). One to one consultations and teaching should be given. Lastly, at the institutional level it is important to make healthcare accessible for the clients and make daily checkups possible, affordable and accessible for the pregnant women and also for the client who are in their reproductive age (Mc Guire, S., 2013).
In a nutshell, diet is an essential component to look after especially for a woman in her reproductive health and for pregnant women. Diet is closely related to and has great impact on a women's reproductive health and has prompt effect on the outcome of pregnancy. There can be many reasons for malnutrition during pregnancy like disease effecting absorption, economic condition of the family and lack of awareness (VerkaikKloosterman, et al, 2102). Steps at individual, community and institutional level are needed to be taken to resolve this rising problem. Development of a proper diet plan for the mother, awareness programs on importance of diet and making healthcare accessible for the clients are some of the necessary steps needed for dealing with this problem.

\section{References}

- Crosignani, P. G. (2006). Nutrition and reproduction in women. Human Reproduction Update, 193-207.

- Hayashi, F., Matsumoto, Y., Momoki, C., Yuikawa, M., Okada, G., Hamakawa, E., Kawamura, E., Hagihara, A., Toyama, M., Fujii, H. and others, (2013). Physical inactivity and insufficient dietary intake are associated with the frequency of sarcopenia in patients with compensated viral liver cirrhosis. Hepatology Research, 43(12), pp.1264-1275.

- Markwald, R., Melanson, E., Smith, M., Higgins, J., Perreault, L., Eckel, R. and Wright, K. (2013). Impact of insufficient sleep on total daily energy expenditure, food intake, and weight gain. Proceedings of the National Academy of Sciences, 110(14), pp.5695--5700.

- $\quad$ Mc Guire, S. (2013). WHO, World Food Programme, and International Fund for Agricultural Development. 2012. The State of Food Insecurity in the World 2012. Economic growth is necessary but 
not sufficient to accelerate reduction of hunger and malnutrition. Rome, FAO. Advances in Nutrition: An International Review Journal, 4(1), pp.126--127.

- Ohlhorst, S. D., Russell, R., Bier, D., Klurfeld, D. M., Li, Z., Mein, J. R., . . .Konopka, E. (2013). Nutrition research to affect food and a healthy lifespan. Advances in nutrition , 579-584.

- Rose, D. and Oliveira, V. (1997). Nutrient intakes of individuals from food-insufficient households in the United States. American Journal of Public Health, 87(12), pp.1956--1961.

- Sharma, R., Biedenharn, K. R., Fedor, J. M., \& Agarwal, A. (2013). Lifestyle factors and reproductive health: taking control of your fertility. Biomed central .
- Valenzuela, R., Ponce, J., MoralesFigueroa, G., Muro, K., Carrel'on, V. and Aleml'an-Mateo, H. (2013). Insufficient amounts and inadequate distribution of dietary protein intake in apparently healthy older adults in a developing country: implications for dietary strategies to prevent sarcopenia. Clinical interventions in aging, 8, p.1143.

- Verkaik-Kloosterman, J., McCann, M., Hoekstra, J. and Verhagen, H. (2012). Vitamins and minerals: issues associated with too low and too high population intakes. Food $\backslash \&$ nutrition research, 56

- Vitolo, M., Campagnolo, P. and Gama, C. (2007). Factors associated with risk of low dietary fiber intake in adolescents. Jornal de pediatria, 83(1), pp.47--52. 